\title{
A VIABILIDADE DE DESENVOLVIMENTO DE PRODUTO ALIMENTÍCIO PARA HIPERCOLESTEROLÊMICOS
}

\section{THE FEASIBILITY OF DEVELOPMENT OF FOOD PRODUCTS FOR HYPERCHOLESTEROLEMICS PATIENTS}

\author{
Camila Lopes Pontinha ${ }^{1}$; Patricia Teixeira Padilha da Silva Penteado ${ }^{2}$; Caroline Augusta \\ Maccoppi ${ }^{1}$; Tais de Oliveira Carlotto ${ }^{1}$. \\ RECEBIDO: MAIO/2005 ACEITO: JULHO/2005 \\ 1. graduados em Farmácia Industrial na UFPR \\ 2. docente da disciplina de Tecnologia de Alimentos Dietéticos, UFPR ppenteado@ufpr.br
}

\begin{abstract}
RESUMO
A busca por alimentos saudáveis vem aumentando progressivamente nos últimos anos, em contraposição ao estilo de vida muitas vezes sedentário e a uma alimentação não balanceada, característica da atual geração. $O$ avanço da ciência na descoberta de doenças genéticas, como a hipercolesterolemia, também contribui para a busca de produtos isentos de colesterol. Deste modo abre perspectivas para o mercado consumidor de produtos alimentícios industrializados que atendam necessidades especiais de alimentação e que, não só, se adapte ao paladar dos consumidores, mas tenham características mais próximas possíveis do produto convencional. Contudo a oferta é insignificante, o que viabiliza o estudo prospectivo e desenvolvimento de produtos de confeitaria isentos de colesterol; salvaguardando a legislação brasileira e os princípios tecnológicos. A formulação selecionada foi modificada aos sabores chocolate com baunilha, laranja e chocolate com aveia, com excelente aceitação e isenta de colesterol. $O$ estudo merece continuidade, como para a vida de prateleira, adequação de embalagem, transposição de massa.
\end{abstract}

Palavras-chave: hipercolesterolemia, bolo sem colesterol, colesterol.

\begin{abstract}
The search for healthy foods is coming progressively increasing lately, in opposition to a sedentary life with a food life-style unhealthy typical of this generation. The scientific advancement about genetics diseases, like hypercholesterolemia also contribute for the search of cholesterol-free food. Thus opportunities are created to answer the special demanding of healthy food that no also it is adapted to the consumer palate with taste as close as the original product. Nevertheless there is no offer, whit makes viable the study and development of cholesterol-free candy-store products. They were development respecting the present legislation about this subject, in laboratorial scale using technological principles. The selected formulations where modified including flavors like chocolate with vanilla, chocolate with oak and orange, all cholesterol-free with great acceptation in the sensorial analysis. The study deserve to be continuated, with shelf-life, packing, mass transpose.
\end{abstract}

Key-word: hypercholesterolemia, free-cholesterol cake, cholesterol

\section{INTRODUÇÃO}

As modificações da composição geral dos alimentos realizadas pelas indústrias causaram grande impacto no hábito alimentar, pois o alto consumo destes alimentos com grande quantidade de gordura, gera desequilíbrio na dieta e impõe medidas educativas nutricionais para balanceá-la. Apesar disto, há por um lado a tendência do aumento das doenças crônicas e degenerativas e do outro lado freqüente diagnóstico de estados nutricionais deficientes na população (OPS,1990). 
A indústria alimentar, aproveitando-se da pressão exercida por nutricionistas, clínicos e consumidores, responde colocando à disposição os alimentos industrializados para fins especiais, como de baixa caloria, com gordura modificada e sem colesterol, ao mercado consumidor (NÓBREGA, 1998). Deste modo se abre ao estudo prospectivo e desenvolvimento de produtos de confeitaria isentos de colesterol; salvaguardando a legislação brasileira e os princípios tecnológicos (pesagem, tamisação, empaste, forneamento, resfriamento e acondicionamento); e cuja elaboração seja viável tanto doméstica quanto industrialmente, mantendo as características sensoriais bem próximas ao produto similar e que atenda às necessidades nutricionais da dieta de pacientes hipercolesterolêmicos. A escolha pelo produto "bolo" justifica-se pela sua grande aceitação por parte da população em geral.

\subsection{HIPERCOLESTEROLEMIA}

O colesterol é um lipídeo anfipático, precursor de todos os hormônios esteróides, dos ácidos biliares, da vitamina $D$ e presente em diversas membranas celulares. Também está nas lipoproteínas plasmáticas sob a livre ou como ésteres de colesterol, influenciando na fluidez e no estado de ativação de enzimas ligadas às membranas (MARTINEZ, 1997). É sintetizado em muitos tecidos a partir do Acetil-CoA, absorvido da alimentação e é eliminado do organismo como colesterol ou sais biliares.

As lipoproteínas são compostos que resultam na associação de lipídeos nãopolares (triacilgliceróis e éster de colesterol) com lipídeos anfipáticos (fosfolipídeos e colesterol) e proteínas. Estes compostos são formados para o transporte das frações lipídicas (insolúveis em água) pelo plasma sanguíneo (MURRAY,1998).

A lipoproteína LDL (low density lipoprotein) é mediadora da captação do colesterol e de ésteres de colesterol por muitos tecidos. Para que as LDL sejam ligadas nos tecidos, é necessária a presença de receptores, mais especificamente, receptores apo B-100 e apo E. Quando estes receptores apresentam anomalias químicas, resultado de alterações genéticas, temos a hipercolesterolemia familial.

A hipercolesterolemia familial é um distúrbio comum autossômico dominante que torna alterado o gene do receptor de LDL, tornando ausente ou deficiente os receptores de LDL, resultando em capacidade diminuída de remover LDL do plasma. Esse distúrbio apresenta-se na forma heterozigota (1 em cada 500 pessoas), onde o paciente possui um alelo anormal, responsável pela não produção de receptores ou produzi-los anormais, geralmente não-funcionais. Neste caso os níveis plasmáticos de LDL estão aumentados de 2 a 3 vezes e o de colesterol excedem a 1\%, comumente na faixa de 300 a $500 \mathrm{mg} / \mathrm{dL}$. A forma homogizota é mais rara (1 em 1 milhão de pessoas) e quase não são encontrados receptores funcionais de LDL, de modo que os níveis plasmáticos de LDL podem estar aumentados de 6 a 10 vezes e os de colesterol podem exceder 800 a 1.000 mg/dL (BENNETT e PLUM, 1997).

Os pacientes com hipercolesterolemia, se não tratados, correm o risco de desenvolver coronariopatia prematura e acelerada, bem como outras manifestações clínicas de arteriosclerose, tais como em pacientes do sexo masculino, o infarto do miocárdio.

Devido à redução na atividade do receptor de LDL, o catabolismo das LDL fica bloqueado e seu nível plasmático aumenta de modo inversamente proporcional à redução nos receptores de LDL. Além do catabolismo reduzido das LDL, sua produção pode estar aumentada. Essa superprodução de LDL, juntamente com o seu 
catabolismo ineficiente, é responsável pela elevada concentração de LDL em pacientes acometidos (MYER e THORN, 1992).

Além dos tipos apresentados, a população sofre também com hipercolesterolemia causada por uma interação complexa de múltiplos fatores genéticos e ambientais, que converge de várias pequenas alterações que afetam a regulação dos níveis de LDL.12 ALIMENTAÇÃO

Os pacientes portadores de hipercolesterolemia devem ser submetidos, além de terapia medicamentosa, a uma dieta com baixo teor de colesterol e gorduras saturadas e ricas em gorduras poliinsaturadas (MYER e THORN,1992). Em alguns casos de hipercolesterolemia heterozigótica os níveis de colesterol diminuem em até $60 \%$, dependendo da medicação.

O tipo de gordura que compõe a dieta tem influencia direta no desenvolvimento de doenças (cardiovasculares, diabetes, câncer) não apenas relacionadas a quantidade mas também pelo tipo de gordura consumida. A alta ingestão de gordura altera o balanço endócrino, a modulação do tipo e da quantidade de eicosanóides produzidos, alterando o metabolismo de energia e/ou as funções imunológicas (MOREIRA et al., 2002). No caso das gorduras poliinsaturadas atuam de maneira protetora, diminuindo a viscosidade do sangue e a formação de trombos (SALUDYALIMENTACION, 2004)

\subsection{ALIMENTOS PARAFINS ESPECIAIS}

A definição de alimentos para fins especiais, segundo a Portaria $n^{\circ} 29$, de 13 de janeiro de 1998 da Agência Nacional de Vigilância Sanitária (ANVISA, 1998), são os alimentos especialmente formulados ou processados, nos quais se introduzem modificações no conteúdo de nutrientes, adequadas à utilização em dietas diferenciadas e ou opcionais, atendendo às necessidades de pessoas em condições metabólicas e fisiológicas específicas.

Estes alimentos devem atender às necessidades fisiológicas pertinentes, classificados e normalizados por regulamentos específicos. De acordo com a Portaria n1015 de 23 de dezembro de 2002 (BRASIL, 2002), que aprova o Protocolo Clínico e Diretrizes Terapêuticas para Dislipidemias, em pacientes de alto risco de desenvolver eventos cardiovasculares, para a hipercolesterolemia recomenda-se dieta pobre em colesterol e gorduras saturadas.

Além da redução da ingestão de produtos de origem animal, ricos em gorduras, e de preparações com leite integral, queijos, ovos, carnes gordas, enlatados, embutidos, manteiga, alimentos submetidos à fritura, pizzas, maionese, óleo de côco e amendoim, etc. é necessário também a redução da ingestão de gorduras "trans" as quais surgem no processo de hidrogenação de óleos vegetais, presentes na maioria das margarinas. Enquanto que é recomendada a ingestão de verduras e hortaliças, de leite e derivados desnatados, carnes magras, óleos vegetais (como girassol, canola, soja), cereais de preferência integrais e macarrão sem ovos.

Para garantir que os produtos alimentícios comercializados com a chamada para regime ou dieta especial atendam a Resolução RCD n ${ }^{\circ} 360$, de 23 de dezembro de 2003 (ANVISA, 2003) devem seguir a obrigatoriedade de declarar a quantidade dos nutrientes, do valor energético correspondente, assim como das gorduras saturadas, trans e colesterol; e a porcentagem diária recomendada de cada nutriente baseada numa dieta diária de $2.000 \mathrm{kcal}$. 


\subsection{O ESTUDO E DESENVOLVIMENTO DE ALIMENTO PARA HIPERCOLESTEROLÊMICOS}

Dentro deste contexto, a necessidade do desenvolvimento de um produto que atendesse às especificações da dietoterapia de pacientes hipercolesterolêmicos e tivesse características sensoriais próximas ao produto convencional foram estudadas. Para minimizar o teor de colesterol do produto pronto - mini-bolo- foram testadas formulações com variedades e proporções diferentes de ingredientes com baixa porcentagem de gorduras saturadas e colesterol.

\section{MATERIAL E MÉTODOS}

\subsection{FORMULAÇÕES}

Na tabela 1 estão apresentadas as principais formulações testadas, a partir de uma massa base de bolo (F1).

TABELA 1: FORMULAÇÕES DE BOLOTESTADAS ( $\mathrm{g} \%)$

\begin{tabular}{|c|c|c|c|c|c|c|c|c|c|}
\hline \multirow[b]{2}{*}{ INGREDIENTES } & \multicolumn{9}{|c|}{ FORMULAÇÕES (\%) } \\
\hline & F1 & $\mathrm{F} 2$ & F3 & F4 & F5 & F6 (1) & F9 & F14(2) & F15 \\
\hline Açúcar refinado & 8,63 & 11,49 & 11,48 & 11,43 & 18,00 & 17,98 & 13,04 & 11,00 & 17,88 \\
\hline Clara de ovo & & & & 16,62 & 16,82 & 16,77 & 16,96 & 16,94 & 16,84 \\
\hline Farinha de trigo & 36,05 & 32,88 & 32,80 & 32,99 & 26,15 & 26,12 & 20,87 & 17,00 & 25,82 \\
\hline Fermento químico & 1,66 & 1,66 & 1,60 & 1,65 & 1,83 & 1,82 & 1,80 & 1,99 & 1,97 \\
\hline Leite desnatado & & & & & & 29,91 & 29,80 & 29,99 & \\
\hline Leite integral & 29,49 & 29,96 & 29,90 & 29,98 & 29,82 & & & & \\
\hline Óleo de soja & 7,42 & 7,41 & 7,62 & 7,53 & 7,38 & 7,40 & 7,47 & 6,98 & 6,96 \\
\hline Ovos (clara + gema) & 16,75 & 16,60 & 16,60 & & & & & & \\
\hline Achocolatado & & & & & & & 9,97 & 9,99 & \\
\hline $\begin{array}{l}\text { Aroma artificial de chocolate e } \\
\text { baunilha }\end{array}$ & & & & & & & 0,09 & 0,10 & \\
\hline Farinha de aveia & & & & & & & & 6,01 & \\
\hline Raspas da casca de laranja & & & & & & & & & 0,70 \\
\hline Suco de laranja & & & & & & & & & 29,83 \\
\hline
\end{tabular}

Nota: (1) F6 foi a escolhida como massa base em face de redução de ingredientes constituídos e favoráveis à presença de colesterol.

(2) deve-se ainda umedecer a aveia em flocos com parte do leite (quantidade suficiente para cobrir os flocos)

\subsection{MODO DE PREPARO DAS FORMULAÇÕES}




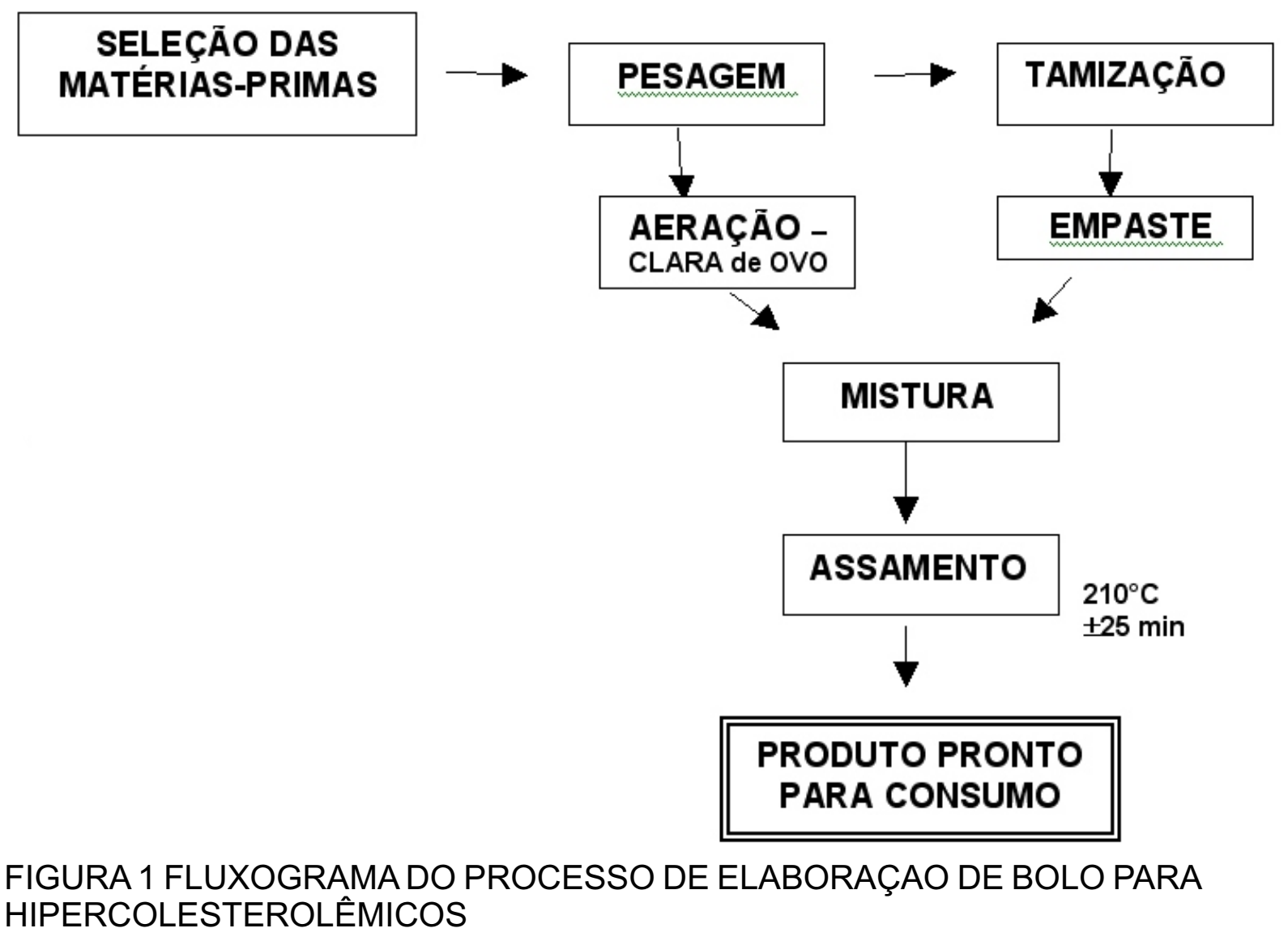

\subsection{AVALIAÇÕESDAQUALIDADE}

A análise sensorial foi realizada para identificar a aceitação das formulações selecionadas, para possíveis adequações ao paladar do consumidor. Para o teste de aceitação foi utilizada a escala hedônica, definida entre "gostei muito" e "odiei", por ser possível a obtenção da provável aceitação de produtos pelo consumidor desde as fases iniciais de desenvolvimento (CHAVES e SPROESSER, 1993) Os atributos avaliados, por 28 provadores não treinados, foram maciez, dulçor, aroma, sabor, leveza, textura e cor. As médias e os desvios padrão foram calculados, evidenciando a formulação de maior aceitação pelas maiores médias nos atributos.

Os valores calóricos e nutricionais foram calculados utilizando tabelas de composição nutricional, seguindo as instruções da resolução RDC $n^{\circ} 360$, de 23 de dezembro de 2003 (ANVISA, 2003).

\section{RESULTADOS E DISCUSSÃO}

\subsection{A REDUÇÃO DO COLESTEROL}


TABELA 01 VALOR NUTRICIONAL E CALÓRICO DAS FORMULAÇÕES DE MINIBOLO PARAHIPERCOLESTEROLÊMICOS

\begin{tabular}{|c|c|c|c|c|c|}
\hline \multirow{2}{*}{ FORMULAÇÕES } & \multirow{2}{*}{$\begin{array}{c}\text { VCT }{ }^{(1)} \\
(\text { Kcal/100g) }\end{array}$} & \multirow{2}{*}{$\begin{array}{c}\text { COLESTEROL } \\
(\mathrm{mg})\end{array}$} & \multicolumn{3}{|c|}{ VN (em 100g de produto pronto) } \\
\hline & & & LIPÍDIOS(g) & CARBOIDRATOS (g) & PROTEÍNAS(g) \\
\hline F1 & 315 & 80,19 & 7,47 & 45,45 & 6,15 \\
\hline F2 & 336 & 79,84 & 11,58 & 39,38 & 6,96 \\
\hline F3 & 338 & 79,84 & 13,41 & 46,04 & 8,21 \\
\hline F4 & 327 & 2,99 & 9,64 & 40,01 & 6,87 \\
\hline F5 & 241 & 2,98 & 2,04 & 41,41 & 6,20 \\
\hline F6 & 285 & $\mathbf{0}$ & 7,69 & 39,88 & 5,49 \\
\hline F9 & 308 & 0 & 12,49 & 41,57 & 7,39 \\
\hline F14 & 331 & 0 & 13,18 & 44,50 & 8,72 \\
\hline F15 & 329 & 0 & 8,57 & 60,77 & 5,33 \\
\hline
\end{tabular}

NOTA: (1) VCT calculado para $100 \mathrm{~g}$ de produto pronto para consumo

A formulação $\mathrm{F} 1$ resultou em massa muito pesada, , pela alta percentagem de farinha de trigo (36,05\%), e baixo dulçor (8,63\% de açúcar refinado); necessitando ajustes na formulação até a F3. A partir desta fase foram realizadas as modificações através dos ingredientes ovo e leite, para redução de colesterol, sendo utilizada apenas clara de ovo; rica na proteína albumina que atua como emulsionante, formando um filme contínuo e coesivo permitindo ligação entre a interface óleo/água da massa. Ainda que se tenham perdas relacionadas às propriedades - umectante, estrutural (proteína), amaciante (gordura) e emulsificante (lecitina) da gema do ovo -, a sua substituição pela quantidade equivalente por clara de ovo aerada conferiu grande maciez e leveza à massa, estrutura e friabilidade similar às formulações $F 1, F 2$ e F3, contudo com perda de dulçor. Esta troca resultou na redução de mais de $96 \%$ de colesterol em relação a F3.

Na formulação F6, a substituição do leite integral por leite desnatado, resultou em formulação isenta de colesterol e de elevada maciez, demonstrando a viabilidade de um produto para hipercolesterolêmicos.

Para maior aceitação do consumidor, ingredientes foram adicionados aos sabores de chocolate com baunilha (F9), de chocolate com aveia (F14) e de laranja (F15) à massa base da formulação F6; entretanto a ausência da gordura do leite e da gema de ovo exigiu o emprego de aromas como realçadores de "flavor" nas formulações F9 e F14.

$\mathrm{Na}$ formulação F15, o leite desnatado foi completamente substituído por quantidade igual de suco natural de laranja, no entanto o sabor laranja não se encontrava de maneira prolongada, isto é, não permanecia presente durante toda a mastigação, somente de maneira fugaz. A adição de aroma artificial de laranja acentuou o sabor em demasia, mesmo em mínimas concentrações $(<0,1 \%)$. A solução encontrada foi utilizar raspas frescas de laranja, que possui óleo essencial, acentuando e mantendo durante a mastigação o sabor.

\subsection{ANÁLISE SENSORIALDASFORMULAÇÕES}


As formulações selecionadas para análise sensorial foram as F14 (= chocolate com aveia) e F15 (= laranja). Os resultados dos atributos avaliados são visualizados na Figura 1, indicando maiores médias para a F15 e conseqüentemente maior aceitação.

FIGURA 1 - PERFIL SENSORIAL (escala 1 - 10) DE FORMULAÇÕES DE MINIBOLO SABOR CHOCOLATE COMAVEIAE LARANJAPARAHIPERCOLESTEROLÊMICOS

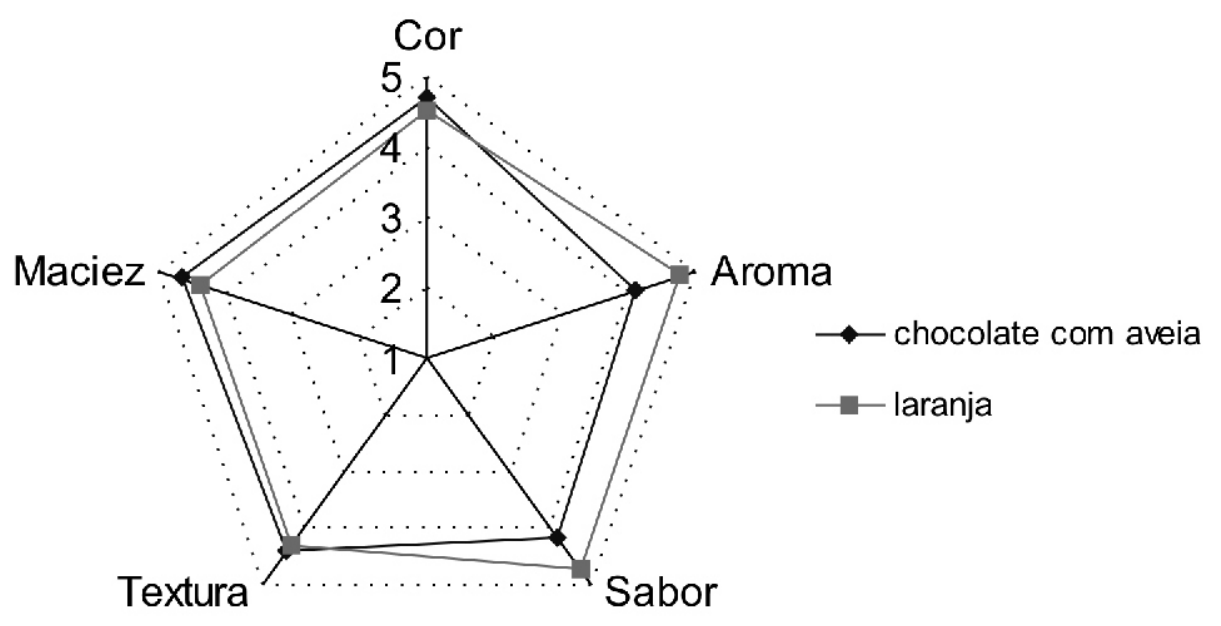

\section{CONCLUSÃO}

As formulações de mini-bolo desenvolvidas encontram-se dentro da definição de alimento para fim especial segundo Portaria da Anvisa $n^{\circ} 29$, de 13 de janeiro de 1998 (ANVISA, 1998) e Portaria SVS/MS n1015, de 23 de dezembro de 2002 (BRASIL, 2002), face às modificações no conteúdo de nutrientes adequados à utilização em dietas diferenciadas e ou opcionais, atendendo às necessidades de hipercolesterolêmicos, para os quais se recomendam dieta pobre em colesterol e gorduras saturadas.

Os resultados das formulações testadas demonstram as possibilidades de produção, em escala doméstica e/ou industrial, de um bolo isento de colesterol e com características sensoriais praticamente equivalentes a de um convencional (e base), ainda inexistente como produto alimentício no mercado consumidor.

A continuidade do presente estudo, sob os aspectos de prazo de validade, transposição de massa, seleção de material para embalagem, etc. Certamente garantirá a oferta de um produto comercialmente seguro para inclusão em dietas de pessoas com necessidades especiais, como as hipercolesterolêmicas.

\section{REFERÊNCIAS}

ANVISA. AGÊNCIANACIONAL DE VIGILÂNCIA SANITÁRIA. Portaria n. ${ }^{\circ} 29$ - SVS/MS de 13 de Janeiro de 1998. Dispõe sobre Regulamento Técnico referente à Informação Nutricional Complementar. Diário Oficial da República Federativa do Brasil, 1998b.(Disponível em: < www.anvisa.gov.br.>) Acesso em: 10/06/2004 
ANVISA. AGÊNCIANACIONAL DE VIGILÂNCIA SANITÁRIA. RDC n 360 - SVS/MS de 23 de dezembro de 2003. Dispõe sobre Regulamento Técnico referente à Rotulagem Nutricional de Alimentos Embalados. Diário Oficial da República Federativa do Brasil. 2003.(Disponível em: < www.anvisa.gov.br.>). Acesso em: 10/06/2004

BENNETT, J.C; PLUM, F. Cecil-Tratado de Medicina Interna. 20ªed. Rio de Janeiro: Guanabara Koogan, 1997. V.1

BRASIL. Portaria SAS/MS No 1015, DE 20/12/2002. Aprova o Protocolo Clínico e Diretrizes Terapêuticas Dislipidemias em pacientes de alto risco de desenvolver eventos cardiovasculares Diário oficial da u n ĩ o $\mathrm{n}^{\circ} 248, \mathrm{de} 24 \mathrm{de}$ dezembro de 2002 . Disponível e m http://www.fesehf.org.br/circulareshtml2002/circular 332.htm Acesso em: 01/10/2204

CHAVES, J.B.P; SPROESSER, R.L. Prática de laboratório de análise sensorial de alimentos e

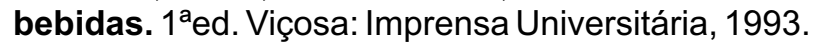

MURRAY, K.R; GRANNER, D.K. Harper: Bioquímica. 8ed. São Paulo: Atheneu,1998.

MYER, M; THORN, W. Harrison:Tratado de Medicina Interna. 12ed. Rio de Janeiro: Guanabara Koogan, 1992. v. 2.

MARTINEZ, T.L.R. Condutas clínicas nas dislipidemias. Belo Horizonte: Health, 1997, $291 \mathrm{p}$.

MOREIRA, N.X.; CURI, R.; MANCINI-FILHO, J. Ácidos graxos: uma revisão. Nutrire, São Paulo, v.24, p.105-123, dez., 2002.

NÓBREGA, F. J. Distúrbios da Nutrição. Rio de Janeiro: Livraria e Editora RevinteR Ltda, 1998.

OPS. Organización Panamericana de la Salud. Conocimientos Actuales sobre Nutrición. $6^{\mathrm{a} e d .}$ Washington: ILSI, 1990.

SALUDYALIMENTACION. Revista Consumer. Fundação Grupo Eroski. Disponível em http://saludyalimentacion.consumer.es/hipercolest/index.html Acesso em: 05/10/2004. 